\title{
Surgical management outcome of cerebral schistosomiasis: a case report and review of the literature
}

\author{
Moayad Moawia ZainElabdin Ahmed ${ }^{1 *}$, Haytham Hussein Mohammed Osman², \\ Alaa Hatim Ameer Mohamed ${ }^{3}$ and Alaaeldin Ginawi ${ }^{4}$
}

\begin{abstract}
Background: Schistosomiasis is a parasitic infection that commonly affects the gastrointestinal and genitourinary tracts. Cerebral schistosomiasis is rare, and few operative cases have been reported in the literature. Diagnosis is usually challenging due to the similarity of the lesion to many other brain conditions. Treatment usually requires surgical resection combined with the use of antiparasitic agents, which often results in good outcomes and excellent prognosis.

Case presentation: A 24-year-old, previously healthy Afro-asiatic man presented to our neurosurgical outpatient clinic complaining of headache and an attack of convulsions. On examination, he had bilateral lower limb weakness more on the right side. Laboratory investigations including stool and urine general test results were unremarkable. Magnetic resonance imaging of the brain was performed and showed an intra-axial left parietal mass; a granulomatous lesion was suggested in the differential diagnoses. The patient underwent craniotomy and total resection of the lesion. Histopathology confirmed the presence of active cerebral Schistosoma mansoni infection. Orally administered praziquantel was initiated at a dose of $20 \mathrm{mg} / \mathrm{kg}$ twice a day for a total of 3 days along with oral administration of corticosteroids for 2 weeks. The patient improved postoperatively without residual weakness and with no further convulsions.
\end{abstract}

Conclusion: Cerebral schistosomiasis is a rare but important consideration in the list of differential diagnoses of cerebral space-occupying lesions. This is of particular importance in in endemic areas like Sudan. In order to reach a diagnosis, careful social and occupational history need to be obtained and correlated with the clinical, laboratory, and radiological findings. Surgical resection along with the use of proper antiparasitic agents usually provides the best clinical outcomes.

Keywords: Cerebral schistosomiasis, Magnetic resonance imaging, Antiparasitic treatment

\section{Background}

Schistosomiasis is estimated to affect more than 200 million people worldwide, who are infected by contact with contaminated water [1]. Central nervous system

*Correspondence: moayadmz@gmail.com

${ }^{1}$ Department of Neurosurgery, Aliaa specialist hospital, P.O.Box 2613,

11111 Omdurman, Khartoum, Sudan

Full list of author information is available at the end of the article manifestations are a result of the inflammatory response to egg deposition; recent infection is usually not present [2]. The commonest cause of cerebral schistosomiasis is Schistosoma japonicum [3], but there are many cases due to Schistosoma mansoni reported in the literature [4]. We report a rare case of active cerebral schistosomiasis in a young male patient presenting with headache and convulsions, where a lesion occupying the left parieto-occipital space was revealed on magnetic resonance imaging original author(s) and the source, provide a link to the Creative Commons licence, and indicate if changes were made. The images or other third party material in this article are included in the article's Creative Commons licence, unless indicated otherwise in a credit line to the material. If material is not included in the article's Creative Commons licence and your intended use is not permitted by statutory regulation or exceeds the permitted use, you will need to obtain permission directly from the copyright holder. To view a copy of this licence, visit http://creativecommons.org/licenses/by/4.0/. The Creative Commons Public Domain Dedication waiver (http://creativeco mmons.org/publicdomain/zero/1.0/) applies to the data made available in this article, unless otherwise stated in a credit line to the data. 
(MRI). The pathology, clinical presentation, diagnostic evaluation, and methods of pre- and postoperative treatment of cerebral schistosomiasis are reviewed.

\section{Case presentation}

A 24-year-old, previously healthy Afro-asiatic man presented to our neurosurgical outpatient clinic complaining of headache for 3 months, which was followed by one attack of generalized tonic-clonic convulsions, which prompted him to seek medical advice. He reported no other associated signs or symptoms. Upon general examination, the patient looked unwell, but no pallor, jaundice, or cyanosis was observed. His vital signs were all within the normal range. On neurological examination, he was conscious, oriented to time, place, and person, with a Glasgow Coma Scale score of 15 out of 15 and normal papillary reaction and size bilaterally. The patient had power grade $4+$ in both the upper and lower right limbs, with normal tone and reflexes in all joints. Systemic review was unremarkable. Laboratory investigations including stool and urine general test results were unremarkable, so no further cerebral spinal fluid analysis was pursued. Initial plain head computed tomography (CT) showed a focal area of high density within the left parietal region. An MRI of the brain was then performed and showed a fairly well-defined $1.8 \times 1 \mathrm{~cm}$ lobulated, cortical-based intra-axial lesion within the left posterior parietal region. The lesion demonstrated homogeneous enhancement and had associated moderate perilesional vasogenic edema with only a mild localized mass effect. No other focal lesions were seen (Fig. 1). A list of possible differential diagnoses was made and included granulomatous lesion, lymphoma, a primary glial neoplasm, and less likely meningioma.
Magnetic resonance spectroscopy, although nonspecific, demonstrated a choline peak suggestive of cell membrane turnover that can be seen in a number of different conditions including neoplasms, demyelination, inflammation, and gliosis. Correlating this with the patient age and history, an inflammatory lesion was thought to be more likely (Fig. 2). The patient was then admitted and underwent craniotomy and total microsurgical resection of the lesion. Histopathology results showed viable and calcified Schistosoma mansoni ova with marked mixed inflammatory infiltrate composed of granulomas and eosinophils, all features consistent with active cerebral schistosomiasis (Fig. 3). Oral administration of antiparasitic praziquantel was initiated at a dose of $20 \mathrm{mg} / \mathrm{kg}$ twice a day for a total of 3 days along with orally administered corticosteroids for 2 weeks. The patient was discharged in good condition with improving neurological condition. A postoperative follow-up MRI was performed 3 months later and showed complete resection of the lesion (Fig. 4). Marked neurological improvement was noted at 1-month, 3-month, and 6-month follow-up visits. The patient regained full power and had no further convulsions.

\section{Discussion}

It is estimated that more than 200 million people worldwide are infected with schistosomiasis after contact with contaminants [1]. Five species are known to infect humans, with Schistosoma japonicum the most common species affecting the human nervous system [3]. Contact with water that carries the larva of the parasite may result in schistosomiasis [5]. After direct contact, the larva enters the human blood through the skin. Days later, worms migrate to the inferior mesenteric
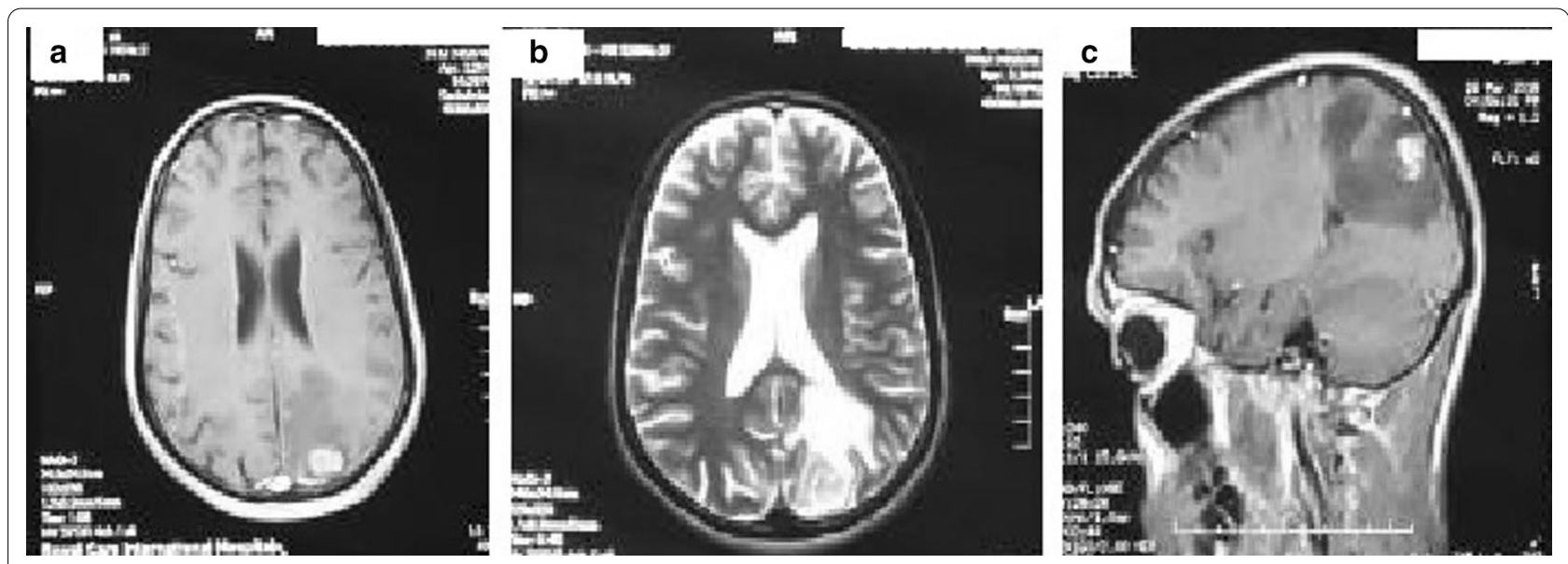

Fig. $1 \mathrm{MRI}$ brain showed left posterior parietal homogenous $1.8 \times 1 \mathrm{~cm}$ enhancing lesion in a) axial T1WI with peri-focal oedema. Lesion fairly defined, irregular, lobulated, intra-axial, cortical based rather than dural based, hyper-intense in $\mathbf{b}$ ) axial T2WI and moderate size peri-lesional oedema in c) sagittal T1WI with contrast 


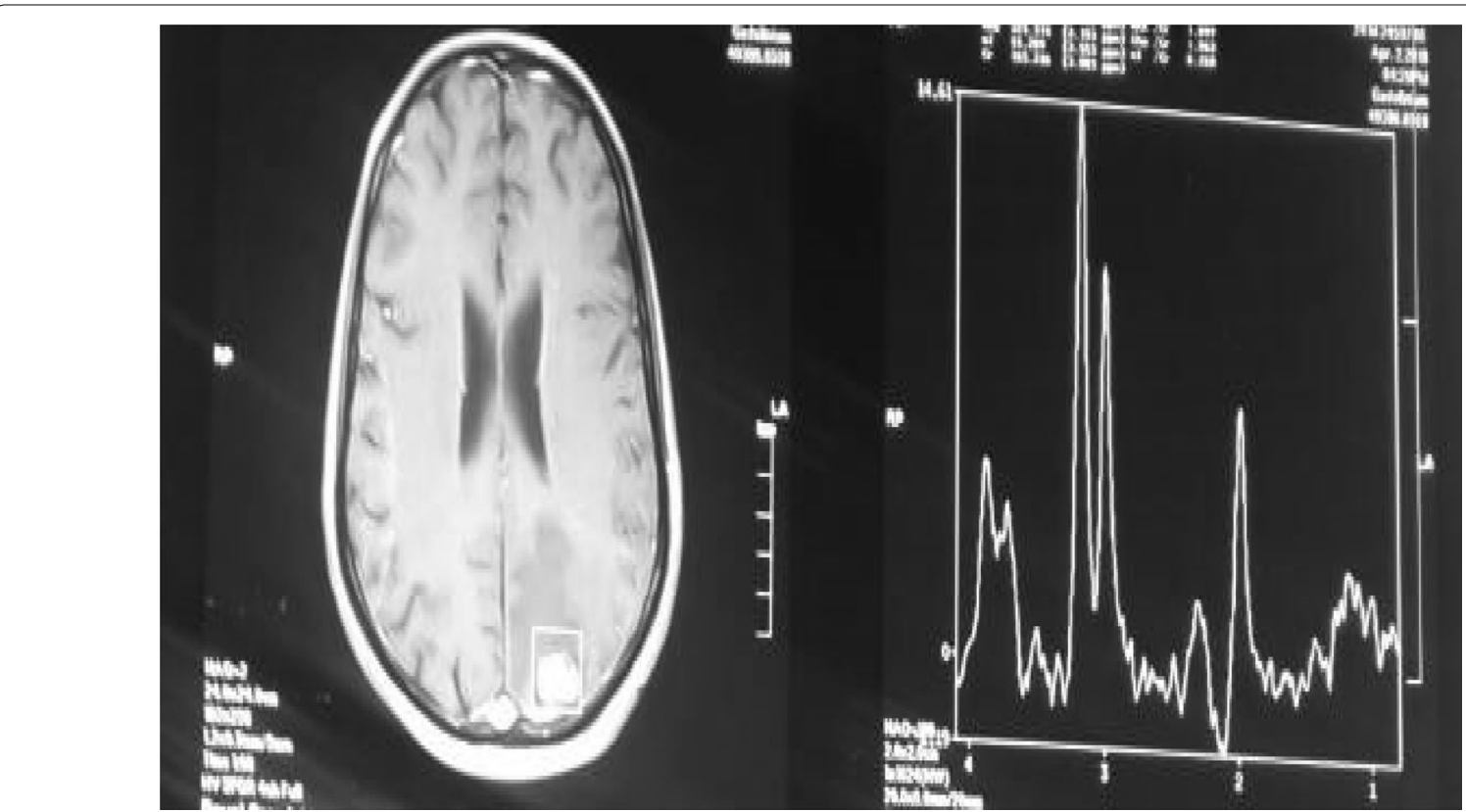

Fig. 2 Magnetic resonance spectroscopy showing choline peak suggesting a process causing rapid cell membrane turnover

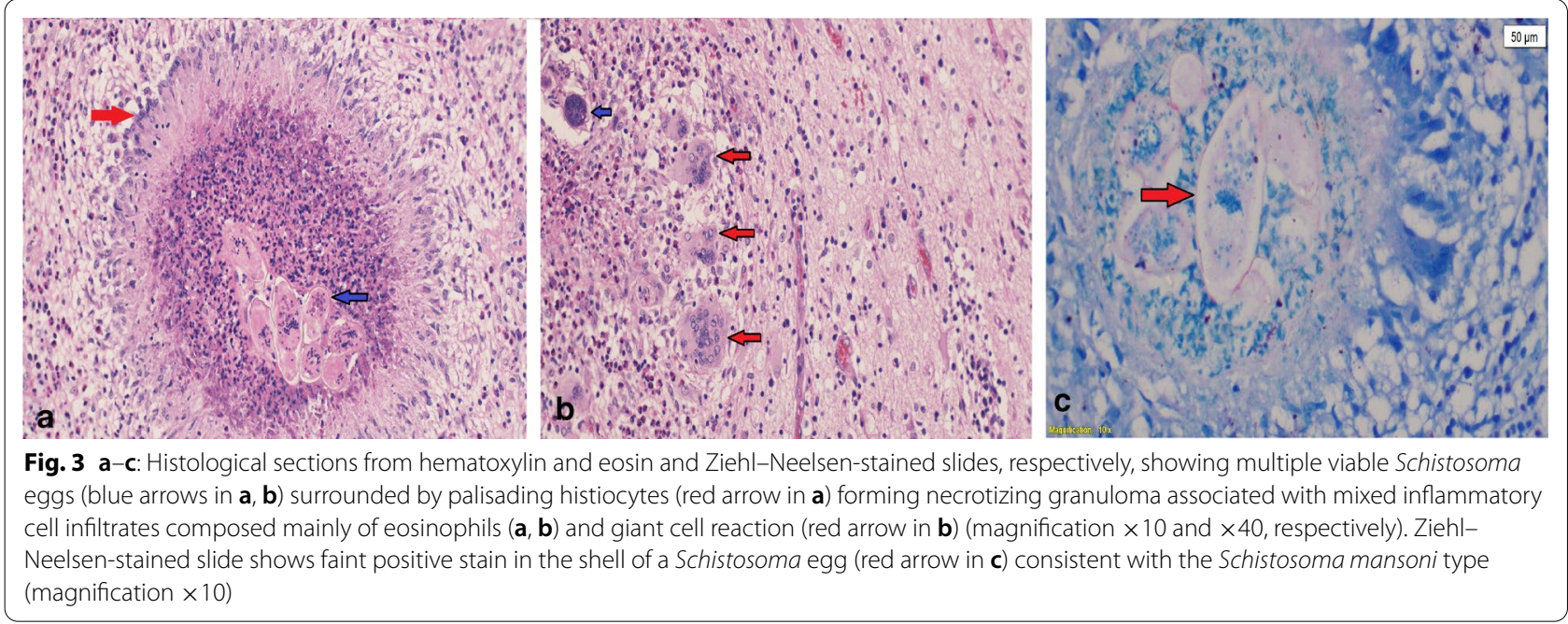

vessels, and the production of eggs begins within 6 weeks following infection [5]. This process continues for the whole life of the worm, or about 3-5 years [6]. The eggs pass through the blood vessel lumen and the intestinal mucosa; they terminate in fecal materials, and the life cycle ends when the eggs release miracidia [5]. The cerebral form of schistosomiasis is thought to result from migration of the worms through the vertebral venous plexus (Batson plexus); in this valveless system, worms are able to migrate and produce eggs directly in the brain [6].
Schistosomiasis of the central nervous system occurs very rarely, with Schistosoma japonicum commonly causing cerebral lesions, and Schistosoma mansoni and Schistosoma haematobium commonly causing spinal cord lesions. Schistosoma mansoni and Schistosoma haematobium are unusual causes of cerebral mass lesions [7]. Pittella et al. reported four patients with cerebral Schistosoma mansoni infection and reviewed a few cases that were reported then in the literature [8].

Central nervous system manifestations are a result of the inflammatory response to egg deposition in the brain and 


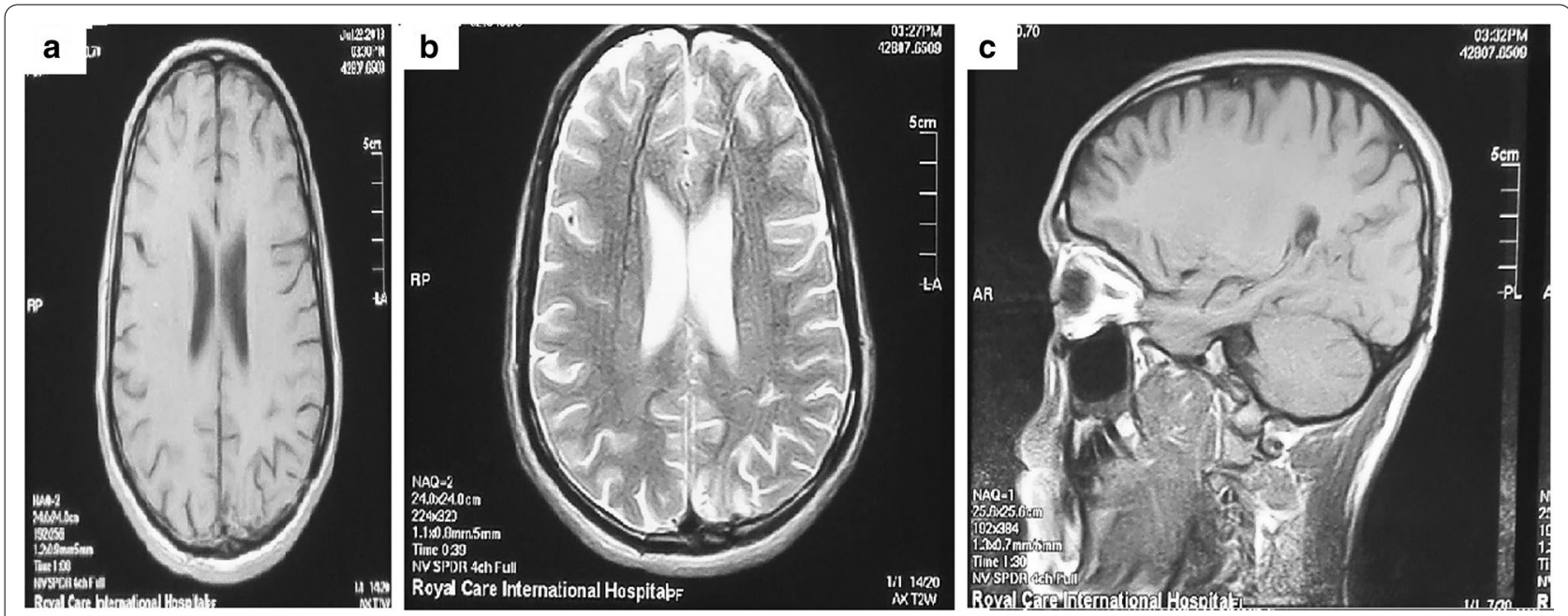

Fig. 4 Post-operative MRI brain showed complete resection of the lesion in a) axial T1WI, b) axial T2WI showed left posterior parietal area of gliosis, c) Sagittal T1WI

spinal cord, and are usually seen in patients with recent infection with no evidence of systemic illness [2]. Supra- or infratentorial foci may result in headache, seizure, and other signs of raised intracranial pressure. Cerebral schistosomiasis is more common in Schistosoma japonicum, but an increasing number of cases due to Schistosoma mansoni have been reported in the literature $[4,6]$.

Schistosomiasis of the spinal cord is a rare condition but is well reported in the literature, especially in sub-Saharan African countries, where several case reports and series have been published. Spinal cord schistosomiasis may present clinically by myelopathy, radiculopathy, or both [9].

In Sudan, a case series was reported in which 5 of 200 patients with spinal cord compression were found to have schistosomiasis and underwent surgery and medical treatment, with excellent outcome; diagnosis of those who underwent surgery was confirmed only after histopathological examination [10]. Another case series of 27 patients was reported by El Malik et al., where all patients underwent regular blood tests, serological investigations, and radiological examination, among which two underwent surgical intervention due to expansion of the lesion with no response to medical management [11].

Operative cases of cerebral schistosomiasis are very unusual and have been reported in the literature on rare occasions. Schistosoma japonicum eggs in the brain were first described by Tsunoda and Shimamura in 1906 [12]. In 1936, Egan et al. reported two neurological cases of Schistosoma japonicum among 12 English sailors who went swimming in the Yangtze River [13].

Patients have been incorrectly diagnosed as having brain tumors, specifically gliomas, due to radiological findings consistent with glioma on CT and MRI [2].
Heterogeneous enhancement was seen mainly at the cerebellum and occasionally at the thalamus, parietal, occipital, and frontal regions $[6,8]$.

Sanelli et al. reported what they called an arborized enhancement pattern with central linear enhancement, which may be significant for cerebral schistosomiasis [14]. Huang et al. concluded that diffusion-weighted MRI with apparent diffusion coefficient values may be a useful tool in the diagnosis of cerebral schistosomiasis [15]. A combination of laboratory and radiological investigations are required in order to reach diagnosis in certain cases [2].

Diagnosis of cerebral Schistosoma infection is a challenging task. Kato-Katz thick-smear stool examination, which is the most practical laboratory examination for the investigation, can determine the presence of eggs in feces [16]. Imai et al. reported the first case of cerebral schistosomiasis due to Schistosoma haematobium, which was diagnosed by molecular methods; polymerase chain reaction assay is a promising method for definitive diagnosis and species identification in cases of cerebral schistosomiasis when Schistosoma ova in urine or stool specimens can be identified [17]. Histopathological examination remains in the only method for reaching a definite diagnosis [1].

The therapeutic strategy in patients with new-onset seizures should be based on the type of seizures and on the epilepsy syndrome. Long-term antiepileptic drug treatment is typically not indicated [6]. The treatment of cerebral schistosomiasis is highly effective and safe; total or partial resection of the lesion is needed to confirm diagnosis and to relieve the signs and symptoms [2]. Medical treatment after diagnosis with oxamniquine and praziquantel, which are the most effective antiparasitic drugs for treating 
schistosomiasis, is essential [6] to kill the adult worms, and corticosteroids reduce granulomatous inflammation and are used for all Schistosoma subtypes [18].

\section{Conclusion}

Surgical management of cerebral schistosomiasis is safe and highly effective in cases where the diagnostic laboratory and radiological findings are inconclusive, leading to difficulty in initiating appropriate medical management. Surgically, total resection of the lesion is the best choice for confirming diagnosis and alleviating symptoms. Medical treatment should be started after surgery and confirmed diagnosis; oxamniquine and praziquantel are effective antiparasitic drugs. These drugs, used alongside corticosteroids, kill the adult worms and reduce the granulomatous inflammation, respectively.

\section{Abbreviations}

MRI: Magnetic resonance imaging; CT: Computed tomography.

\section{Acknowledgements}

The authors acknowledge the great efforts and precise histopathology information provided by Professor Ali Abdel Satir.

\section{Authors' contributions}

MMZA collected the data including patient history, radiological and pre- and postoperative images, surgical intervention, and regular follow-ups, and was the major contributor. $\mathrm{HO}$ collected the data concerning the physical examination, with main contribution to the operative procedure and regular follow-ups. AM collected the data concerning the histopathological examination. AG contributed to the manuscript by analysis of the patient's radiological images, and wrote the case presentation and discussion parts of the manuscript regarding radiological features of the disease and its relevant literature review, and revised the manuscript. All authors read and approved the final manuscript.

\section{Funding}

The authors received no financial support for the research, authorship, or publication of this article.

\section{Availability of data and materials}

All data generated or analyzed during this study are included in this published article and its supplementary information files.

\section{Declarations}

\section{Ethics approval and consent to participate}

Ethical approval was obtained.

\section{Consent for publication}

Written informed consent was obtained from the patient for publication of this case report and any accompanying images. A copy of the written informed consent is available for review by the Editor-in-Chief of this journal.

\section{Competing interests}

The authors declare that they have no competing interests.

\section{Author details}

'Department of Neurosurgery, Aliaa specialist hospital, P.O.Box 2613, 11111 Omdurman, Khartoum, Sudan. ${ }^{2}$ The National Ribat University, Neurospine Center, Ribat University Hospital, Khartoum, Sudan. ${ }^{3}$ Histo-center, Khartoum Hospital Street, Khartoum, Sudan. ${ }^{4}$ Queens Medical Centre, Nottingham University Hospitals, Nottingham, UK.
Received: 6 June 2020 Accepted: 26 March 2021

Published online: 23 May 2021

\section{References}

1. Ribas J, Escobio PF, Morillo MG. Clinical case of cerebral schistosomiasis. Tropical Medicine and International Health. 2011. Retrieved from http:// ovidsp.ovid.com/ovidweb.cgi?T $=$ JS\&PAGE $=$ reference\&D $=$ emed10\& NEWS $=N \& A N=70590021$.

2. Wu L, Wu M, Tian D, Chen S, Liu B, Chen Q, Guo Z. Clinical and imaging characteristics of cerebral schistosomiasis. Cell Biochem Biophys. 2012;62(2):289-95. https://doi.org/10.1007/s12013-011-9294-1.

3. Gjerde IO, Mörk S, Larsen JL, Huldt G, Skeidsvoll H, Aarli JA. Cerebral schistosomiasis presenting as a brain tumor. Eur Neurol. 1984;23(4):229-36. https://doi.org/10.1159/000115735.

4. Coyle CM. Schistosomiasis of the nervous system. Handb Clin Neurol. 2013;114:271-81. https://doi.org/10.1016/B978-0-444-53490-3.00022-4.

5. Ross AGP, Bartley PB, Sleigh AC, Olds GR, Li Y, Williams GM, McManus DP. Schistosomiasis. N Engl J Med. 2002. https://doi.org/10.1056/NEJMra0123 96.

6. Betting LE, Pirani C, De Queiroz LS, Damasceno BP, Cendes F. Seizures and cerebral schistosomiasis. Arch Neurol. 2005;62(6):1008-10. https://doi. org/10.1001/archneur.62.6.1008.

7. Pollner JH, Schwartz A, Kobrine A, Parenti DM. Cerebral schistosomiasis caused by Schistosoma haematobium: case report. Clin Infect Dis. 1994;18(3):354-7. https://doi.org/10.1093/CLINIDS/18.3.354.

8. Pittella JEH, Da Silva Gusmão SN, Carvalho GTC, Da Silveira RL, Campos GF. Tumoral form of cerebral schistosomiasis mansoni. A report of four cases and a review of the literature. Clin Neurol Neurosurg. 1996. https:// doi.org/10.1016/0303-8467(95)00075-5.

9. Algahtani HA, Aldarmahi AA, Al-Rabia MW, Baeesa SS. Acute paraplegia caused by Schistosoma mansoni. Neurosciences (Riyadh). 2014;19(1):47-51.

10. Salim AD, Arbab MA, El Hassan LA, El Hassan AM. Schistosomiasis of the spinal cord: report of 5 cases from Sudan. East Mediterr Health J. 2012. https://doi.org/10.26719/2012.18.3.294.

11. Fatih $E, E I M B$, Surgical F, et al. Original article Neuroschistosomiasis in Sudan. Sudan Med J. 2011;47(2):75-85.

12. Tsunoda T, Shimamura S. Contribution to the pathological anatomy of the so-called Katayama disease, to the aetiology of the cerebral vessels embolism and Jackson's ... Wchnschr. 1906

13. Egan CH. An Outbreak of Schistosomiasis japonicum. J R Nav Med Serv. 1936;22(1):6-18. Retrieved May 28, 2020, from https://www.cabdirect. org/cabdirect/abstract/19362901082.

14. Shih R, Koeller KK. Bacterial, fungal, and parasitic infections of the central nervous system: radiologic-pathologic correlation and historical perspectives. Radiographics. 2015. https://doi.org/10.1148/rg.2015140317.

15. Huang J, Luo J, Peng J, Yang T, Zheng H, Mao C. Cerebral schistosomiasis: diffusion-weighted imaging helps to differentiate from brain glioma and metastasis. Acta Radiol. 2017;58(11):1371-7. https://doi.org/10.1177/ 0284185116687.

16. Fundação NK, Cruz O. A simple device for quantitative stool thick-smear technique in Schistomiasis Mansoni New schistomicidal and molluscidal compounds View project. researchgate.net. 1971. Retrieved from https:// www.researchgate.net/publication/18489942.

17. Imai K, Koibuchi T, Kumagai T, Maeda T, Osada Y, Ohta N, Fujii T. Cerebral schistosomiasis due to Schistosoma haematobium confirmed by PCR analysis of brain specimen. J Clin Microbiol. 2011. https://doi.org/10. 1128/JCM.01073-11.

18. George J, Rose D, Hazrati L-N, Majl L, Hodaie M. Cerebral schistosomiasis-an unusual presentation of an intracranial mass lesion. Can J Neurol Sci. 2009. https://doi.org/10.1017/S0317167100006624.

19. Chang T, Smith GW, Riesenman FR, Alston EF. Cerebral granuloma due to schistosomiasis. J Am Med Assoc. 1948;136(4):230-8. https://doi.org/10. 1001/jama.1948.02890210014003.

\section{Publisher's Note}

Springer Nature remains neutral with regard to jurisdictional claims in published maps and institutional affiliations. 